\title{
AQUECIMENTO GLOBAL E A EDUCAÇÃO FÍSICA: A CONSCIENTIZAÇÃO A PARTIR DA CORRIDA DE ORIENTAÇÃO
}

João Victor de Mello Avelino ${ }^{1}$

Soraya Correa Domingues ${ }^{2}$

Resumo: O presente estudo envolve as áreas de Educação Física escolar e Educação Ambiental. Tem como objetivo geral descrever e analisar alternativas para uma conscientização dos alunos acerca do aquecimento global, a partir das aulas de Educação Física. Foi feito uma pesquisa de abordagem qualitativa do tipo bibliográfica de natureza explicativa. O aquecimento global é um assunto de extrema relevância para a vida no planeta, pois algumas de suas consequências são o degelo, aumento do nível dos oceanos, queimadas incontroláveis e outros. Ao final do estudo se expõe uma possibilidade de trabalhar essa temática nas aulas de Educação Física a partir da corrida de orientação de forma interdisciplinar.

Palavras-chave: Educação Física Escolar. Educação Ambiental. Interdisciplinar. Possibilidade. Explicativo.

Abstract: This study involves the areas of school Physical Education and Environmental Education. Its general objective is to describe and analyze alternatives to raise students' awareness of global warming, based on Physical Education classes. A qualitative research of the bibliographic type of explanatory nature was carried out. Global warming is a matter of extreme relevance to life on the planet, as some of its consequences are melting, rising sea levels, uncontrollable fires and others. At the end of the study, there is an opportunity to work on this topic in Physical Education classes from the orientation race in an interdisciplinary way.

Keywords: School Physical Education. Environmental education. Interdisciplinary. Possibility. Explanatory.

${ }^{1}$ Universidade Federal do Paraná. E-mail: jv.avelino1510@gmail.com.

2Universidade Federal do Paraná. E-mail: domingues.soraya@gmail.com

Revbea, São Paulo, V. 15, № 7: 20-32, 2020. 


\section{Introdução}

Já não é de hoje que muito se discute sobre o aquecimento global que vêm acontecendo no planeta Terra. Muitas medidas vêm sendo tomadas por governos e as organizações. Mas o que vem sendo ensinado e como está sendo trabalhado esse tema na educação formal da escola básica? Já é do notório saber que esse tema é mais explorado pela disciplina de Geografia, ou Ciências naturais, por estar envolvido com clima, inversões, temperatura, meio ambiente. Mas existem possibilidades para abordar tal temática nas outras áreas de modo interdisciplinar.

Analisando a lei 9.7595/99, denominada como lei da Educação Ambiental, vemos que a transmissão do conhecimento acerca do aquecimento global é possível em todas as disciplinas, inclusive na Educação Física. É um tema da Educação Ambiental que consta na lei como um conteúdo transversal, porém há uma problemática para além da toeira: será que os professores da atualidade estão lidando com essa temática tão importante para nós e principalmente para o planeta e a sobrevivência de todos? E na área da Educação Física, como é possível explorar essa temática nas aulas para o conhecimento dos alunos?

Dentro da escola a Educação Ambiental vem tentando organizar um processo pedagógico para formar pessoas com atitudes conscientes em relação ao seu meio ambiente, esse processo é organizado a partir de princípios sistematizados pelo tratado para as Sociedades Sustentáveis e Responsabilidade Global (DA TERRA, 2000). No Brasil esse tratado impactou em formular a Política Nacional de Educação Ambiental, que assegura no âmbito educativo o ensino sobre sustentabilidade, abrindo precedentes para atuação e formação de professores e estudantes ambientalistas.

A Educação Ambiental está cada vez mais presente no cotidiano da Educação Física escolar, por conta das atividades que relacionam a natureza e o ser humano, inclusive previstas na Base Comum Curricular, com a indicação das práticas corporais de aventura (BRASIL, 2017). A partir desse contexto, surge a seguinte indagação: como o professor pode organizar aulas para conscientizar os alunos acerca do aquecimento global na prática de ensino da Educação Física? Para responder essa pergunta, o estudo tem como objetivo geral descrever e analisar alternativas para uma conscientização dos alunos acerca do aquecimento global a partir das aulas de Educação Física. E como objetivos específicos: a) identificar teorias e explicações acerca do aquecimento global, Educação Ambiental e corrida de orientação; b) descrever uma possível possibilidades metodológicas nas aulas de Educação Física.

Por meio desse tipo de estudo é possível entender mais sobre o assunto relevante e essencial, nos dias atuais, para a sobrevivência humana no planeta Terra. Alguns de nós, mesmo depois de adultos não temos consciência do que esse assunto se trata, nem suas definições ou suas características. A abordagem dessa temática na educação básica deve pressupor uma aproximação prazerosa e lúdica possibilitando uma conscientização para

revista brasileira educação ambiental 
estudantes de diversas idades, importante para a construção de um mundo melhor, mais equilibrado entre o ser humano e natureza.

\section{Metodologia}

Para compor o estudo foi feito uma pesquisa de abordagem qualitativa do tipo bibliográfica de natureza explicativa (CRESWELL, 2007). Foi realizada busca em sites de pesquisas e de periódicos científicos, nos três últimos anos, com objetivo de identificar, selecionar, realizar leitura e análise sobre: estudos publicados que abordam o aquecimento global; a corrida de orientação e Educação Física; Educação Ambiental. Foi realizada uma leitura na íntegra das pesquisas selecionadas, destacando trechos para compor explicações sobre conceitos relacionados ao tema. Também foi realizada análise de documentos legais que dispõe sobre a Educação Ambiental, bem como suas diretrizes na Educação Nacional e a Base Nacional Comum Curricular.

As análises das pesquisas relacionadas indicaram características sobre o aquecimento global, práticas e metodologias de corrida de orientação nas aulas de Educação Física e possibilidades para trabalhar com a Educação Ambiental, seus objetivos e princípios, e a Educação Física com base nas diretrizes sobre as práticas corporais de aventura como conteúdo para a escola básica.

Após aproximações com a bibliografia e documentos relacionados a temática, foi criado uma proposta metodológica para prática de ensino sobre o aquecimento global como possibilidade para abordar a Educação Ambiental na escola nas aulas de Educação Física. Considerando que está disposto em lei, nas diretrizes LDB (BRASIL, 1996) e na Base Nacional Comum Curricular (BNCC). Essa proposta da prática de ensino é o resultado de uma reflexão teórica considerando as condições atuais da escola. Já que a primeira atitude de pesquisa foi aproximação com a realidade da escola para realização de observação de campo, com intuito de identificar temas atuais e relevantes para a vida, e especificamente para a Educação Física escolar. Buscando com isso estudar e pesquisar sobre a temática ambiental na Educação Física escolar para refletir, pensar e indicar possibilidades metodológicas de acordo com sua cultura e sua realidade.

\section{Revisão}

Durante a fase escolar de crianças e adolescentes muito se ouve falar sobre clima, mudanças climáticas e principalmente aquecimento global, que são temas interessantes ao ser humano e também que estão sendo muito discutidos pela sociedade em geral. $E$ entre os estudantes, muitos ouvem ou leem sobre o assunto e estão preocupados com o que vêm acontecendo com o planeta Terra em consequência desse aquecimento. 
A cada ano que passa, a temperatura média na Terra aumenta, causando inúmeras consequências que ameaçam a vida nesse planeta. Uma dessas consequências é o degelo nos Andes Meridionais, porém, ele é apenas uma das dezenas que existem, pois, o aumento da temperatura impacta em muitos fatores que mexem com o planeta, como: mudanças climáticas, secas, queimadas, entre outras.

Pesquisadores especialistas no campo encontraram um aumento de gases chamados "gases-estufa" na atmosfera, esses são: dióxido de carbono (CO2), metano (CH4), óxido nitroso (N2), ozônio (03), e clorofluorcarbonos (CFCs), esses casos potencializam o efeito estufa, resultando no aumento da temperatura na Terra.

Segundo Conti (2005, p. 70),

essas substâncias sofreram um aumento significativo em consequência da ação antrópica, tais como a queima de combustíveis fósseis, fruto da industrialização em grande escala, expansão de áreas urbanas, desmatamentos e queimadas de grandes volumes de biomassa, multiplicação do rebanho bovino, cujo processo digestivo libera metano e também produzido pela decomposição do carbono em ambiente anaeróbico, como ocorre em pântanos e em reservatórios construídos para gerar hidroeletricidade à custa de submergir enormes extensões de florestas, o óxido nitroso por sua vez, resulta de práticas agrícolas inadequadas.

Já é fato que o aquecimento global vem aumentando com o passar dos dias, as causas desse fenômeno são múltiplas, como por exemplo a poluição, que vem desde a pessoa que joga seu lixo na rua e em lugares inapropriados só para se livrar daquele material. Essa prática resulta em entupimentos de bueiros (tendo complicações em possíveis enchentes), em poluição de rios e oceanos, além disso dependendo do material, o mesmo pode demorar mais de 200 anos para se decompor, como é o caso do plástico.

Outro fator causador do aquecimento global é o desmatamento, muitas das vezes praticado pela venda ilegal da madeira, essa prática está crescendo cada vez mais na Amazônia e vem causando sérias complicações à vida humana. O desmatamento sem o devido reflorestamento diminui o número de árvores do planeta, causando uma menor troca de gás carbônico por oxigênio pelas árvores. O aquecimento global também causa queimadas, que dependendo da região aumenta a emissão dos gases-estufa na atmosfera, e devasta, acabando com tudo o que há no local. As queimadas são mais comuns em regiões com clima seco, e cada vez mais esse cenário está ficando comum, reter uma propagação da queimada, quando ela é avistada, é difícil, devido à proporção que ela cresce. 
As consequências desses problemas ambientais resultam em inúmeros fatores negativos e ameaçadores à vida na Terra. $O$ fator do aumento da temperatura média do planeta, torna o clima ainda mais seco e tóxico o qual já é notório para o senso comum, principalmente nos grandes centros urbanos, nos quais há polo industrial. Ao aquecimento se desdobram outros fatores como o degelo dos polos do planeta, que causam aumento gradativo no nível dos oceanos, desequilibrando as relações entre as espécies e o seu habitat, e preocupando populações, principalmente, as que moram em regiões costeiras ao mar, realidade de muitos brasileiros.

Outro fator preocupante também é outra consequência do aquecimento global: o efeito estufa. Um efeito natural, que com o aumento da temperatura média do planeta esse efeito tende a aumentar. Segundo Conti (2005) o efeito estufa "constitui-se de $40 \%$ gases e $60 \%$ de vapor d'água, o agente mais ativo desse efeito, esse vapor d'água é distribuído por toda a atmosfera global, e junto com o aquecimento global essa sensação térmica aumenta". O estudioso francês Paul Acot do Centre National De Recherches Scientifiques (CNRS), da França, propôs duas hipóteses particularmente inquietantes: aumento da média térmica do globo em até $4,0^{\circ} \mathrm{C}$ até 2050 , afetando mais o hemisfério norte, em virtude da inércia térmica do hemisfério sul, predominantemente oceânico e aumento de até 1 metro, ou mais, no nível dos oceanos, no mesmo período. Sabendo-se que $80 \%$ da população mundial habita zonas costeiras, avalia-se o impacto de tal fenômeno (ACOT, 2003).

Podemos perceber que o aquecimento global é um tema que reflete a atual desequilibrada relação ser humano e natureza, preocupando as populações em todo o planeta e mobilizando política governamentais e não governamentais em torno de ações para conscientizar e alterar essas atuais relações desequilibradas. Esse cuidado com o ambiente e esse incentivo a uma educação voltada para pensar o equilíbrio ambiental está atualmente, no Brasil, disposto na Lei da Educação Ambiental, que versa sobre objetivos, princípios e conceito, tornado uma dimensão que organiza dentro e fora da escola, ambientes educacionais voltados a refletir sobre as ações do ser humano com o seu ambiente.

Entre várias definições sobre o que é a Educação Ambiental, destaca-se que, para Medina (2001, p.17),

a Educação Ambiental pode ser definida como um processo, que consiste em propiciar às pessoas uma compreensão crítica e global do ambiente, para elucidar valores e desenvolver atitudes que lhes permitem adotar uma posição consciente e participativa a respeito das questões relacionadas à conservação e a adequada utilização dos recursos naturais, deve ter como objetivos a melhoria da qualidade de vida, a eliminação da pobreza extrema e do consumismo desenfreado. 
Segundo Jacobi (2003, p. 193) "cabe destacar que a Educação Ambiental assume cada vez mais uma função transformadora, na qual a responsabilização dos indivíduos torna-se um objetivo essencial para promover um novo tipo de desenvolvimento - o desenvolvimento sustentável'. Esse autor demonstra a importância da responsabilidade que cabe a Educação Ambiental de transformar o indivíduo para ter hábitos, práticas e atitudes mais sustentáveis.

No Brasil a lei que dispõe sobre a Educação Ambiental a lei foi prevista na constituição de 1988, e é importante para o atual cenário mundial diante aos desequilíbrios que se percebe nos problemas ambientais. A lei 9.795 de 27 de abril de 1999 sobre Política Nacional da Educação Ambiental, conceitua a Educação Ambiental como um processo no qual o indivíduo e a coletividade constroem valores sociais, conhecimentos sobre o assunto, atitudes que devem ser tomadas e em busca de uma humanização da população voltada para a conservação do meio ambiente, bem como a racionalidade do uso da natureza, para uma boa qualidade de vida sustentável para todos, meta da Educação Ambiental.

Associada a Lei 9.795, a resolução №2, de 15 de junho de 2012, estabelece Diretrizes Curriculares Nacionais para a Educação Ambiental Interdisciplinar, indicando que ela deve estar presente em todas as áreas e em todas as disciplinas, bem como em todos os níveis de ensino, desde a Educação Infantil ao Ensino Superior. Nas instituições de ensino ela deve ser ensinada como um tema interdisciplinar e transversal de forma ampla e integral. $\mathrm{E}$ aos órgãos inerentes as políticas sobre o meio ambiente há programas e ações práticas para a Educação Ambiental destinadas à conservação, recuperação e melhoria do meio ambiente. Aos meios de comunicação de massa há de colaborar para expandir as informações e conhecimentos sobre práticas educativas sustentáveis. Às empresas, entidades de classe, instituições públicas e privadas devem existir programas destinados à formação e capacitação dos trabalhadores em que diz respeito ao controle do meio ambiente, visando sua melhoria. À sociedade como um todo, há de manter uma atenção permanente à formação de valores, atitudes e habilidades que propiciem a atuação individual e coletiva voltada para a prevenção, a identificação e a solução de problemas ambientais.

$\mathrm{Na}$ lei constam diversos princípios básicos e objetivos fundamentais da Educação Ambiental. Há também algumas disposições gerais no que diz respeito a medidas a serem tomadas para estudar metodologias, produzir materiais didáticos, especializações, formação de profissionais, atendimentos específicos, tecnologias avançadas, e difusão dos conhecimentos relacionados à Educação Ambiental e também dispõe sobre a responsabilidade do órgão responsável pela Educação Ambiental, bem como a criação das diretrizes e regulamentações.

No que diz respeito a apresentação da Educação Ambiental, os princípios e os objetivos que essa temática engloba está bem definido, mas há 
um déficit na disseminação e realização sobre o que diz nesses documentos. Segundo Adams (2010, p.2152) "a pesquisa traz outro resultado que confirma a necessidade de divulgação para apropriação desta ferramenta pelo corpo docente para aprimorar e disseminar essa prática educacional", quando indica que "[...] a temática ambiental está presente tanto no trabalho dos professores como no material didático, mas não é trabalhada interdisciplinarmente como determina a legislação de Educação Ambiental" (OLIVEIRA, 2009, s/p).

A partir desse estudo surgem questionamentos acerca da formação de professores e como a Educação Ambiental está presente nessa formação, será que ela está sendo como deve ser? Será que está presente?

Para Adams (2010, p.2154),

isso não está sendo efetivo, há uma necessidade de elaborar um programa de capacitação ou minicurso para equipes pedagógicas e equipes diretivas para que estas tenham não somente acesso aos documentos referência que balizam a EA, mas que também possam vivenciá-los através de atividades dinâmicas e de reflexão para o aprimoramento das práxis da Educação Ambiental, podendo, estes, tornarem-se multiplicadores.

Para a formação de professores, especificamente de Educação Física Domingues, Kunz e Araújo (2011) apontam que "algumas particularidades são limitadoras ao trabalho pedagógico relacionado a Educação Ambiental: a fragmentação do conhecimento nos cursos de formação de professores de Educação Física e o caráter esportivo das disciplinas".

Apesar das dificuldades na realidade da formação de professores, a Educação Ambiental está cada vez mais presente no cotidiano da Educação Física escolar por conta das atividades que relacionam a natureza e o ser humano (INÁCIO; MARINHO, 2007). Essas atividades são consideradas pelos profissionais de Educação Física como atividades da natureza, e os estudos sobre elas vêm sendo aprofundado pelos pesquisadores (FIGUEIREDO; SCHWARTZ, 2013). Porém, as atividades de aventura não podem apenas se apropriar da natureza para ser realizada, deve haver uma conscientização da relação ser humano e natureza na perspectiva da Educação Ambiental. Segundo Jacobi (2003) "o educador tem a função de mediador na construção de referências ambientais e deve saber usá-los como instrumentos para o desenvolvimento de uma prática social centrada no conceito da natureza".

Como citado acima, a formação de caráter esportivo dificulta a implementação de projetos ambientais na formação de professores, além disso as dicotomias existentes e a fragmentação do curso também deixam o trabalho mais difícil. "A Educação Ambiental deve ser trabalhada em uma perspectiva ambiental, levando em consideração aquele contexto inserido" (DOMINGUES; 
KUNZ; ARAÚJO, 2011). Quando relacionada ao esporte, a apropriação da natureza pode estar facilmente associada a indústria esportiva, ao consumismo e alienação das próprias práticas esportivas. Neste sentido, é necessário trabalhar as práticas corporais de aventura, para a conscientização ambiental, como estratégias para mudança de conduta do ser humano com a natureza.

$\mathrm{Na}$ dimensão da Educação Ambiental a Educação Física se sita como um campo de atuação profissional para contribuir com ambientes de educação para a conscientização e ações ambientais. Para isso a conscientização deve começar desde o curso de formação de professores que irão atuar com a Educação Física. Para que o professor tenha fundamentos teóricos e metodológicos para atuar na educação adequando as experiências e vivências das práticas esportivas e de aventura na natureza na Dimensão da Educação Ambiental.

Uma das maneiras possíveis de relacionar a Educação Ambiental com o conteúdo previsto no currículo de Educação Física é com a temática de práticas corporais de aventura. Como citado anteriormente, a Educação Ambiental deve ser trabalhada como um tema transversal e interdisciplinar, relacionando a mesma com as práticas corporais na natureza e contextualizando sentidos e significados da realidade ambiental em projetos interdisciplinares com outras áreas em torno da temática ambiental, como a geografia, história, matemática, ciências e Educação Física.

O conteúdo "práticas corporais de aventura" está prevista na Base Nacional Comum Curricular (2017, p.178) e é definido como,

expressões e formas de experimentação corporal centradas nas perícias e proezas provocadas pelas situações de imprevisibilidade que se apresentam quando o praticante interage com um ambiente desafiador. Algumas dessas práticas costumam receber outras denominações, como esportes de risco, esportes alternativos e esportes extremos. Assim como as demais práticas, elas são objeto também de diferentes classificações, conforme o critério que se utilize. Neste documento, optou-se por diferenciá-las com base no ambiente de que necessitam para ser realizadas: na natureza e urbanas. As práticas de aventura na natureza se caracterizam por explorar as incertezas que o ambiente físico cria para o praticante na geração da vertigem e do risco controlado, como em corrida orientada, corrida de aventura, corridas em mountain bike, rapel, tirolesa, arborismo etc. Já as práticas de aventura urbanas exploram a "paisagem de cimento" para produzir essas condições (vertigem e risco controlado) durante a prática de parkour, skate, patins, bike etc. 
Nesse sentido, a proposta é relacionar as práticas corporais de aventura com a Educação Ambiental, pois estas práticas já oferecem em seu conteúdo a relação com a experiência, vivência e percepção da natureza como um ambiente em que o ser humano vive e pertence. Segundo Villela e Morais (2013) "os esportes de aventura e o meio ambiente configuram-se num tema abordado por outros autores também, que veem a possibilidade de discutir questões de problemas ambientais, preservação e sensibilização através dessa prática comum em ambientes naturais".

Bahia e Sampaio (2005) afirmam que, por meio da prática dessas atividades de aventura, abre-se um caminho para o desenvolvimento da conscientização ambiental. Assim, as experiências vividas de tais práticas podem ser uma oportunidade para o surgimento de novas atitudes e sentimentos, podendo unir as vivências corporais e o respeito pelo meio ambiente.

Para trabalhar esses aspectos nas aulas de Educação Física e trazer um sentido de conscientização, destaca-se a corrida de orientação como tema para contextualizar o aquecimento global. Antes de refletir sobre essa possibilidade é preciso entender sobre as definições de corrida de orientação, suas técnicas, normas regras e suas características gerais.

A corrida de orientação então, pode ser entendida como uma modalidade rica em atributos, podendo ser praticada individualmente, em grupo ou em família, andando ou correndo através da natureza, ou em outros ambientes. É uma grande aventura que requer inteligência, astúcia, concentração, análise e domínio de si mesmo, entre outras virtudes. Ela pode ser vivenciada, também, como uma ferramenta motivadora em outros campos do conhecimento, por isso há um caráter interdisciplinar pregado. "Os alunos podem familiarizar-se com as outras disciplinas tais como: geografia, biologia, matemática, história etc., além da identificação de símbolos cartográficos" (PASINI; DANTAS, 2003).

Um percurso é montado no mapa do ambiente em que a corrida irá ser realizada, vários pontos de controle são distribuídos pelo terreno e marcados no mapa, esses são chamados de "prismas". O caminho que a pessoa irá seguir entre um ponto e outro fica a critério do participante, porém a passagem por todos os pontos de controle é obrigatória. Então, a escolha do melhor itinerário é importante para o resultado. A vitória da corrida pode ser para o participante que realiza o percurso em menos tempo ou apenas em caráter exploratório.

\section{Possibilidades na prática de ensino}

Com o intuito de trabalhar com a Educação Ambiental nas aulas de Educação Física, tematizando o aquecimento global, iremos nos aproximar da corrida de orientação, refletindo sobre as possibilidades em determinado contexto escolar para indicar a prática de ensino. Para tais reflexões teóricas 
sobre a prática será considerado a realidade de uma escola na cidade de Curitiba/PR 3 e oferta turmas do $1^{\circ}$ ao $5^{\circ}$ ano. A proposta pedagógica é um projeto interdisciplinar sobre a corrida de orientação, contextualizando questões pertinentes a outras áreas escolares em torno do o aquecimento global, suas causas, consequências e conceituação. As aulas são planejadas em conjunto com outros professores e podem ser desenvolvidas ao longo do ano para a realização da aula de experiência e vivencia com a prática da corrida de orientação. O estudante entra em contato com 0 assunto por diversas abordagens, aprofundando as questões em torno do aquecimento global. A corrida de orientação pode ser, inclusive prepara e planejada pelos próprios estudantes juntamente com os professores ao longo das aulas interdisciplinares, até que eles possam se apropriar do conhecimento específico sobre a corrida de orientação e do aquecimento global para experimentar e vivenciar a prática. Na corrida de orientação os estudantes devem encontrar o seu caminho a ser percorrido através de resolução de problemas e questões sobre o aquecimento global, aprofundando e se fundamentando sobre a temática de modo lúdico e integral.

A experiência prática pode ser realizada da seguinte forma: trabalhar com 4 grupos que podem ser de uma mesma turma, ou até várias turmas diferentes. No dia previsto para a atividade será feita uma concentração dos quatro grupos em um espaço grande, que pode ser uma quadra ou gramado, cada grupo deverá ser marcado com uma cor (verde, vermelho, amarelo e azul) e revisar um pouco acerca da corrida de orientação que já será feita anteriormente em aulas interdisciplinares. Os alunos não necessitarão de bússola, apenas de um mapa da planta da escola onde consta a concentração deles no espaço inicial e a localização exata na planta, essa poderá ser construída com os próprios alunos, dos seis prismas que estarão espalhados pela escola. Os prismas no mapa devem ser representados por um círculo vermelho.

Cada grupo receberá um mapa da planta da escola e papel na forma de gabarito nessa constará em branco seis perguntas com quatro alternativas cada uma. Dada a largada cada grupo terá que se dirigir até os prismas (independente da sequência), chegando nele terá uma pessoa organizadora com a pergunta acerca do aquecimento global, essa pergunta deverá ser respondida na folha de gabarito e não pode ser rasurada, o grupo também ao sair desse prisma deverá pegar um papel com o responsável referente à cor do seu grupo, para comprovar no final da corrida que passou por lá em algum momento da corrida.

Quando todos os grupos chegam até o final do percurso, novamente no espaço inicial, passando pelos seis prismas, será feita a contagem dos pontos, o valor máximo de pontos é referente a dez, quatro destinado ao tempo e seis

${ }^{3}$ Esse colégio foi observado durante o período de estágio no Curso de Licenciatura em Educação Física. 
para as perguntas. A turma que terminar o percurso no menor tempo terá o valor máximo de quatro pontos, $2^{\circ}$ melhor tempo: três pontos, $3^{\circ}$ melhor tempo: dois pontos e o pior tempo apenas hum ponto. Quando todos os grupos retornarem ao espaço inicial será corrigido o gabarito com as respostas (Tabela 1), cada resposta certa vale hum ponto, podendo totalizar seis pontos no máximo. Ganhará a turma que mais obtiver pontos, a maneira de condução da divulgação dos resultados e premiações fica à critério dos organizadores.

Tabela 1: Gabarito individual de cada grupo.

\begin{tabular}{lllll}
\hline GRUPO: & A) & B) & C) & D) \\
\hline PRISMA 1 & A) & B) & C) & D) \\
\hline PRISMA 2 & A) & B) & C) & D) \\
\hline PRISMA 3 & A) & B) & C) & D) \\
\hline PRISMA 4 & A) & B) & C) & D) \\
\hline PRISMA 5 & A) & B) & C) & D) \\
\hline PRISMA 6 & & & \\
\hline TEMPO TOTAL DO PERCURSO: & & & \\
\hline QUANTIDADE DE ACERTOS:
\end{tabular}

Fonte: Os autores (2019)

Com isso, a corrida de orientação pode ser uma prática corporal de aventura para trabalhar o aquecimento global na perspectiva da Educação Ambiental na Educação Física escolar, garantindo o conhecimento específico da Educação Física e envolvendo outras áreas de conhecimento em projeto interdisciplinar, que não termina na experiência da prática, mas busca a partir desta experiência a vivência e a percepção do ambiente como um lugar para se respeitar e viver em equilíbrio.

\section{Considerações Finais}

O presente estudo teve como objetivo geral descrever e analisar alternativas para uma conscientização dos alunos acerca do aquecimento global a partir das aulas de Educação Física. Esse estudo é importante para a clareza de ideias sobre os conceitos e teorias acerca do fenômeno aquecimento global, a Educação Ambiental e as possibilidades de trabalho no campo da Educação Física. Esse tipo de estudo bibliográfico de natureza explicativa é importante porque identifica os fatos que determinam ou contribuem para a ocorrência dos fenômenos. O estudo se limita na identificação de uma visão geral vista de cima de várias medidas que são tomadas para auxiliar positivamente nesse fim, porém, o que se tenta elucidar aqui é uma conscientização acerca da temática. Outro fator limitante é o desafio de se pensar maneiras de trabalho interdisciplinar com um único tema, porém sabemos que é possível.

O aquecimento global é um assunto que deve ser mais discutido e trabalhado não só pela comunidade acadêmica e cientifica ou de forma breve 
na educação básica. Ela deve ser ensinada como um tema transversal em todas as disciplinas, sem exclusão. A Educação Ambiental é de suma importância para os seres humanos que habitam a Terra, isso tem que ser sistematizado e claro para os escolares desde os primeiros anos da escola, até a sua saída. E não só na escola, mas em como todas as instituições a Educação Ambiental deve estar presente e de forma forte. Sabemos que em alguma parte do mundo talvez pelo egoísmo e pelo individualismo próprio ainda não se ligou ou não se importa com as mudanças que o mundo vem apresentando em relação às mudanças dos elementos naturais, muitas causadas pela ação humana.

Relacionar aquecimento global com a Educação Física é um desafio, mas foi possível graças a corrida de orientação, temos que levar em consideração alguns aspectos relacionados aos alunos e ao tempo em que eles têm para a apropriação do conteúdo acerca do aquecimento global, mas a proposta das perguntas está cabível para ser realizada em qualquer contexto educativo, com turmas que já tiveram pelo menos a base da temática aquecimento global. Esse trabalho contribui para a comunidade acadêmica de forma a fornecer uma proposta de realização e também explicações e noções acerca do tema apresentado talvez ainda não tão claras à alguns indivíduos, organizações, instituições, famílias e outras malhas sociais.

\section{Referências}

ACOT, P. Histoire du climat. Paris, Éditions Perrin, p. 309, 2003.

ADAMS, B. G. A importância da Lei 9.795/99 e das diretrizes curriculares nacionais da Educação Ambiental para docentes. Revista Monografias Ambientais, v. 10, n. 10, p. 2148-2157, 2012.

BAHIA, M. C.; SAMPAIO, T. M. V. Lazer-meio ambiente: Em busca das atitudes vivenciadas nos esportes de aventura. Revista Brasileira de Ciências do Esporte, v. 28, n. 3, 2007.

BRASIL. Constituição da República Federativa do Brasil. Brasília: Senado Federal, 1988.

BRASIL. Lei no 9.394, de 20 de dezembro de 1996. Estabelece as diretrizes e bases da educação nacional. Diário Oficial da União, Brasília, 23 de dezembro de 1996. Disponível em: <http://www.planalto.gov.br/ccivil_03/leis/L9394.htm>. Acesso em: 23 mar. 2017.

BRASIL. Lei no 9795 - 27 de abril de 1999. Dispõe sobre a Educação Ambiental. Política Nacional de Educação Ambiental. Brasília, 1999. Disponível em: http://www.planalto.gov.br/ccivil 03/leis/19795.htm. Acesso em: 20/04/2019.

BRASIL. Ministério da Educação. Secretaria da Educação Básica. Base nacional comum curricular. Brasília, DF, 2017. Disponível em: http://basenacionalcomum.mec.gov.br/images/BNCC El EF 110518 versaofin al site.pdf. Acesso em: 20/04/2019. 
BRASIL. Resolução no2, de 15 de junho de 2012. Que estabelece as Diretrizes Curriculares Nacionais para a Educação Ambiental. DOU no 116, Seção 1, págs. 70-71 de 18/06/2012. Disponível em: http://portal.mec.gov.br/dmdocuments/rcp002 12.pdf. Acesso em: 20/04/2019.

CONTI, J. Considerações sobre as mudanças climáticas globais. Revista do Departamento de Geografia, v. 16, p. 70-75, 30 abr. 2011.

CRESWELL, J. W. Projeto de pesquisa: métodos qualitativo, quantitativo e misto; tradução Luciana de Oliveira da Rocha - 2ed - Porto Alegre: Artmed, 2007.

\section{DA TERRA, Carta. A carta da Terra. 2000.}

DE OLIVEIRA, M. E. A Temática Ambiental no Ensino Médio. Disponível em: http://www.educacao.ufpr.br/publicacoes/sedpeef/resumos comunicacao \%20 oral \%20 em \%20pdf/mariaeunice.pdf. Acesso em: 23/04/2019.

DOMINGUES, S. C.; KUNZ, E.; DE ARAÚJO, L. C. G. Educação Ambiental e Educação Física: possibilidades para a formação de professores. Revista Brasileira de Ciências do Esporte, v. 33, n. 3, 2011.

JACOBI, P. R. Educação Ambiental, cidadania e sustentabilidade. Cadernos de pesquisas, n. 118, p. 189-205, 2003.

MEDINA, N. M. A formação dos professores em Educação Ambiental. In: Panorama da Educação Ambiental no ensino fundamental / Secretaria de Educação Fundamental - Brasília; MEC; SEF, 2001. Disponível em: $<$ http://portal.mec.gov.br/secad/arquivos/pdf/coea/panorama.pdf\#page=17>. Acesso em: 10/05/2019.

PASINI, C. G. D.; DANTAS, M. Disciplina de orientação e o currículo de Educação Física do ensino superior: uma inclusão necessária. Resumo da Dissertação de Mestrado em Educação pela Universidade Vale do Rio Verde de Três Corações, 2003.

VILLELA, P. M.; MORAIS, S. 2013. Temas e Possibilidades de Educação Ambiental nas Aulas de Educação Física. (Apresentação de trabalho/comunicação). Disponível em: http://cepedgoias.com.br/edipe/vedipefinal/pdf/gt06/co\%20grafica/Pollyana\%20 de\%20Macedo\%20Villela.pdf. Acesso em: 13/05/2019. 